\section{Commentary: Leaving tricuspid regurgitation unrepaired at the time of left ventricular assist device implantation?}

\author{
Michael N. D’Ambra, MD
}

Gomez Hamacher and colleagues describe the impact of tricuspid valve insufficiency on the performance of left ventricular assist devices (LVADs). ${ }^{1}$ They created an ovine model of left heart failure using coronary ligations in 10 animals. The animals were allowed to recover for 2 to 3 weeks, after which they were placed on bypass and underwent LVAD implantation. Five animals also had surgically induced tricuspid regurgitation (TR).

The authors found that in the situation of isolated left heart failure, LVAD performance was not significantly impacted in the TR group, except for a reduction in LVAD outflow relative to the no-TR group. This may be a physiological response of the LVAD to reduced inflow. Sudden imposition of severe TR in a normally functioning right ventricle reduces forward stroke volume as regurgitant flow occurs. Reduced right ventricular (RV) stroke volume translates into reduced pulmonary venous inflow and reduced inflow to the device.

The study question is based on the clinical dilemma of what to do about tricuspid insufficiency when placing an LVAD. Unfortunately, the authors' choice of an left ventricular coronary ligation model and a short recovery period results in pure left ventricular failure with normal RV function. Thus, their study design narrows the utility of the model to answer the study question, because preserved

From the Harvard Medical School (ret), University of Maryland School of Medicine, Baltimore, Md.

Disclosures: The author reported no conflicts of interest.

The Journal policy requires editors and reviewers to disclose conflicts of interest and to decline handling or reviewing manuscripts for which they may have a conflict of interest. The editors and reviewers of this article have no conflicts of interest.

Received for publication Sept 26, 2020; revisions received Sept 26, 2020; accepted for publication Oct 1, 2020; available ahead of print Nov 2, 2020.

Address for reprints: Michael N. D'Ambra, MD, Division of Cardiac Surgery, University of Maryland School of Medicine, Baltimore, MD 21201 (E-mail: mdambra@ gmail.com).

JTCVS Open 2020;4:24

2666-2736

Copyright $(2020$ The Authors. Published by Elsevier Inc. on behalf of The American Association for Thoracic Surgery. This is an open access article under the CC BY license (http://creativecommons.org/licenses/by/4.0/).

https://doi.org/10.1016/j.xjon.2020.10.001

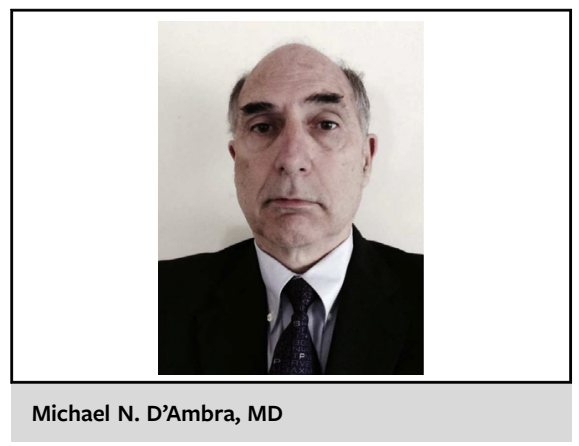

CENTRAL MESSAGE

Leaving TR unrepaired at the time of LVAD implantation?

RV function does not often occur in the scenario of LVAD placement. However, there are cases with preserved RV function and TR, and the authors' findings have applicability for these patients.

The impact on LVAD performance is a consideration when contemplating whether to leave an LVAD patient with TR. Other considerations, such as the effects of TR on renal function ${ }^{2}$ and hepatic function, ${ }^{3}$ also must be included in the decision making calculus, as must the potential negative effects of an intervention on the tricuspid valve on repair durability and efficacy. ${ }^{4}$

This remains an important and irksome study question. We look forward to hearing more from these authors in the future.

\section{References}

1. Gomez Hamacher CJR, Torregroza C, Sadat N, Scheiber D, von der Beek JC, Westenfeld R, et al. Impact of tricuspid valve insufficiency on the performance of left ventricular assist devices. J Thorac Cardiovasc Surg Open. 2020;4:16-23.

2. Maeder MT, Holst DP, Kaye DM. Tricuspid regurgitation contributes to renal dysfunction in patients with heart failure. J Card Fail. 2008;14:824-30.

3. Lau GT, Tan HC, Kritharides L. Type of liver dysfunction in heart failure and its relation to the severity of tricuspid regurgitation. Am J Cardiol. 2002;90:1405-9.

4. Barac YD, Nicoara A, Bishawi M, Schroder JN, Daneshmand MA, Hashmi NK, et al. Durability and efficacy of tricuspid valve repair in patients undergoing left ventricular assist device implantation. JACC Heart Fail. 2020;8:141-50. 